\title{
Factors associated with asthma control: MOSAR study (Multicenter Observational Study of Asthma in Rabat-Morocco)
}

\author{
Imane Ghanname ${ }^{1,2^{*}}$, Ahmed Chaker ${ }^{3}$, Abha Cherkani Hassani ${ }^{4}$, Laila Herrak ${ }^{5}$, Serge Arnaul Ebongue ${ }^{6}$,
} Mustapha Laine ${ }^{7}$, Khalid Rahhali ${ }^{3}$, Abdelhak Zoglat $^{3}$, Aida Maria Benitez Rexach ${ }^{8,9}$, Samir Ahid ${ }^{1}$ and Yahia Cherrah ${ }^{1}$

\begin{abstract}
Background: The purpose of the study is to describe the profile of patients with asthma and to identify the signifiant risks and the protective factors associated with asthma control.

Methods: A prospective epidemiological study was conducted in three hospitals of Rabat-Morocco and included 396 patients with asthma. Differences in characteristics across the levels of asthma control were compared by the one-way analysis of variance for continuous variables, and chi-square test was used for categorical variables. The risk and protective factors associated with the asthma control levels were determined by Proportional Odds Model (POM) for bivariate and multivariate ordinal logistic regression, also expressed as Odds Ratios (OR) and 95\% Confidence Intervals (95\% Cl).

Results: From 7440 patients screened by 28 physicians, 396 were included in study. 53\% of the particiants sufferd controlled, 18\% had partly controlled and $29 \%$ had uncontrolled asthma symptoms. A multivariate ordinal logistic regression analysis showed that having respiratory infections $(A O R=5.71)$, suffering from concomitant diseases $(A O R=3.36)$ and being allergic to animals $(A O R=2.76)$ were positively associated with poor control of asthma. However, adherence to treatement $(A O R=0.07)$, possession of health insurance ( $A O R=0.41)$ and having more than 2 children $(A O R=0.47)$ were associated with good asthma control.

Conclusion: The study established a clinical-epidemiological profile of asthmatic patients in Rabat region in Morocco. By ordinal logistic regression we found that 6 factors - respiratory infections, concomitant diseases, animals allergy, adherence to treatment, health insurance and having more than two children - were associated with asthma control.
\end{abstract}

Keywords: Asthma control, Epidemiology, Ordinal logistic regression, Proportional odds model, Protective factors, Risk factors

\section{Background}

The World Health Organization estimates that there are now 235 million asthmatics worldwide [1] and more than 17 million of this individuals are in the United States [2]. In Morocco, 3.89\% of the Moroccan population was affected by asthma, in 2009, which represents more than 1.2 millions people [3].

\footnotetext{
* Correspondence: gh.imane@hotmail.fr

${ }^{1}$ Research team of Pharmacoepidemiology \& Pharmacoeconomics,

Laboratory of Pharmacology and Toxicology, Faculty of Medicine and

Pharmacy, Mohammed V University, Rabat, Morocco

${ }^{2}$ Faculty of Health Sciences, International University of Casablanca, Bouskoura, Morocco

Full list of author information is available at the end of the article
}

Prevalence of asthma varies, from 1 to $18 \%$ depending on the countries [4-9], its much cost, also its unpredictable evolution and the possibility to prevent its exacerbation, make asthma a capricious disease that forms a public health priority [10].

Despite the rapid progress of its knowledge, understanding the evolution of asthma is still insufficient. However, some deadly forms could be avoided through better supervision and better education of patients [2].

Studies in French populations showed there are 2000 deaths annually due to asthma, most of them could be avoided [2] and less asthma patient care often leads to severe forms that need hospitalization. Furthermore,

(C) The Author(s). 2018 Open Access This article is distributed under the terms of the Creative Commons Attribution 4.0 International License (http://creativecommons.org/licenses/by/4.0/), which permits unrestricted use, distribution, and 
nearly $50 \%$ of the asthmatic population does not take the prescribed treatment [11].

Current clinical practice displayed phenotypic characterization of asthma is difficult [12, 13]. Therefore, pragmatic decisions are necessary according to each patient [14]. A better understanding of the health status of each asthma patient and the evolution of this condition may provide (i) the appropriate patient prevention of the disease in adhering to prescriptions and medical advice, (ii) and aid clinicians to provide improved coping therapies and protocols to prevent adverse conditions leading to disease deterioration.

The study about the evaluation of anti-asthmatic drugs consumption in Morroco [15] demonstrated that despite its high prevalence [3], the therapeutic care of asthma remains unsatisfactory at the national level compared to other countries, probably due to a combination of factors; the very particular socioeconomic environment of the developing countries with its corollaries (low purchasing power ...); the part of the generic drug and the insubstantial health insurance which is poorly distributed; in addition to the inherent difficulties to asthmatic patients (influence beliefs) and the absence of national recommendations about asthma care.

This research aims to describe the clinicalepidemiological profile of asthmatic patients included in MOSAR study (Multicenter Observational Study of Asthma in Rabat). Furthermore, check their asthma control levels and identify the major risks and the protective factors associated with asthma control in the actual clinical practice of the care of asthma in Morocco.

\section{Methods}

\section{Study design}

MOSAR (Multicenter Observational Study of Asthma in Rabat) is a prospective observational study conducted on 42 months (from September 2010 to April 2014) in three hospitals of Rabat (Ibn Sina Hospital, Mohamed V Military Hospital and Moulay Youssef Hospital) on a sample of 396 asthmatic patients.

During this period, for each patient included in the study, physicians had to fill out a ad-hoc questionnaire, based on GINA guidelines and validated by experts, concerning asthma control level, sociodemographic, environmental and clinical characteristics and medications use. The date of inclusion in study is the date of the first contact with the patient.

A feasibility study was conducted in the three hospitals within the research to assess the validity and quality of the ad-hoc questionnaire.

\section{Study population}

Among the consultants of pulmonology and allergology and according to GINA guidelines [16], adult patients were included in the study if they had a physician diagnosis of asthma for at least 3 months (to avoid entanglements with bronchiolitis [17]). The diagnosis was based on medical history, physical examination, and spirometry.

We have noticed across the different departments of pneumology in our study that the indivuduals who smoke more than 10 pack-years of cigarettes consulted were diagnosed with Chronic Obstructive Pulmonary Disease (COPD). We excluded them from our list automatically.

Patients with Bronchiectasis or Cardiac Asthma (a medical diagnosis of wheezing, coughing or shortness of breath due to congestive heart failure were also excluded from this study.

\section{Guidelines}

GINA International guidelines [16] concern diagnosis, severity, treatment, monitoring and education of asthmatic patients.They permit adequate care management of the severity of asthma, with the aim of mastering the disease. The levels of severity and control were determined by combining several criteria: the frequency of diurnal and nocturnal symptoms, their impact on the activity and the sleep, and the results of lung function, use of inhaled short acting beta2-agonists (SABAs) and sever exacerbation [18].

\section{Ethics}

The study protocol was approved by Ethics Committee for Biomedical Research (CERB) of the Faculty of Medicine and Pharmacy of Rabat performed in accordance with the Declaration of Helsinki, good clinical practice, and all relevant international and national legislations and written informed consent for participating in the study was also obtained from all participants.

\section{Variables}

The dependent variable was asthma control. Patients were classified into 3 groups: controlled, partly controlled and uncontrolled asthma symptoms.

\section{The independent variables were:}

- Socio-demographic variables: age, sex, Body Mass Index (BMI), marital status, number of children, residence, educational level, occupation and health insurance.

- Environmental and clinical variables: season of consultation, reasons of visit, duration of asthma, family history of asthma, active and passive smoking, presence or absence of concomitant diseases, comorbidities (rhinitis, allergic conjunctivitis, gastroesophageal reflux (GERD), respiratory infections), nocturnal awakenings, number of crisis, symptoms 
during 3 previous months (expectoration, wheezing, dyspnea, nocturnal coughing), presence or absence of allergies, lung function, and adherence to treatment.

\section{Statistical analysis}

Continuous variables were described by mean and standard deviation $( \pm S D)$ and categorical variables by absolute and relative frequencies. Differences in characteristics across the level of asthma control were compared by the one-way analysis of variance for continuous variables and a chi-square test was used for categorical variables. Values of $P<0.05$ were considered significant in a bilateral approach.

The factors associated with the asthma control levels were determined by Proportional Odds Model (POM) for ordinal logistic regression. This regression model for ordinal data leading to the estimate of a single odds ratio that gives the risk to go from controlled to partly controlled asthma and from partly controlled to uncontrolled asthma (briefly "from controlled to uncontrolled asthma").

A univariate ordinal logistic regression analysis was completed to separately examine the association of each factor with the asthma control levels (using controlled asthma as the reference category). Then, all factors with a statistical significance of $p$-value $<0.05$ in the univariate analysis were included into a multivariate ordinal logistic regression.

The final models were built using stepwise selection factors method with a $p<0.05$ significance level. The proportional odds assumption was tested with the Brant test (line parallelism), and the Hosmer-Lemeshow goodness-of-fit test was used to validate the model.

A database was automatically developed from the questionnaire in Form Designer of Epi Info software (version 3.5.1) and all statistical analysis were performed using SPSS (Statistical Package for the Social Sciences) (IBM 13.0 for Windows ${ }^{\circ}$ ).

\section{Results}

From September 2010 to April 2014, a total of 7440 patients visited the pneumology allergology services and were screened by 28 physicians. Only 396 patients $(5.3 \%$ of the patients in pulmonology consultants for distinct reasons) met the inclusion criteria and were eligible for the study. Furthermore, among them, there were $211(53 \%), 72(18 \%)$ and $113(29 \%)$ patients who had respectively controlled, partly controlled and uncontrolled asthma symptoms (Fig. 1).

\section{Profile of patients with asthma \\ Socio-demographiccharacteristics}

The socio-demographic characteristics of the study population were divided into three groups to represent

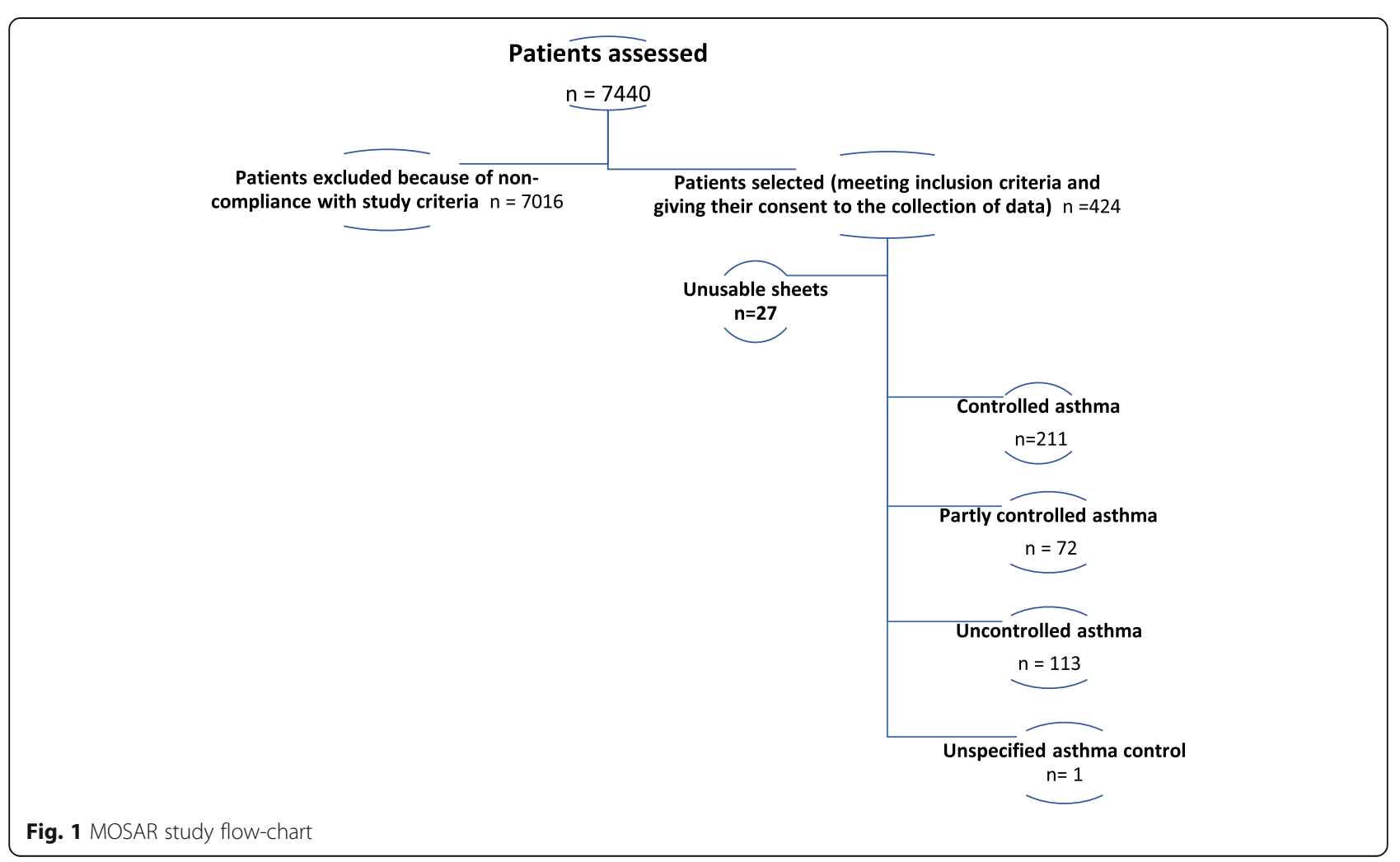


the respective three levels of asthma control, presented in tables.

The socio-demographic factors that differed significantly with asthma control levels were: age, civil status, number of children and health insurance (Table 1).

The average age was 42 years and more than half of the patients (51.3\%) were between 40 and 64 years old; higher proportion of older patients were found in the controlled asthma group.

$76.7 \%$ of patients were married and the ratio of married patients varied significantly across the three control levels from $15.5 \%$ in partly controlled to $27.7 \%$ and $56.8 \%$ in uncontrolled and controlled asthma respectively $(p=0.025)$. Among the health insured patient population, $60.4 \%$ of the participants were considered as controlled, $15.8 \%$ and $23.8 \%$ as partly controlled and uncontrolled respectively $(p<0.05)$.

No differences were showed on sex, BMI, the place of residence, educational level, and occupation among the three groups of patients (Table 1). Also, 266 of patients were females (67.3\%) and the majority were in the categorized under the uncontrolled asthma group, conversely to men (31.2\% versus $23.3 \%)$. Furthermore, less than the half had an average weight or were underweight

Table 1 Socio-demographic characteristics of the studypopulationaccording to levels of asthma control

\begin{tabular}{|c|c|c|c|c|c|}
\hline & $\begin{array}{l}\text { All } \\
n=396\end{array}$ & $\begin{array}{l}\text { Controlled } \\
n=211(53 \%)\end{array}$ & $\begin{array}{l}\text { Partly controlled } \\
n=72(18 \%)\end{array}$ & $\begin{array}{l}\text { Uncontrolled } \\
n=113(29 \%)\end{array}$ & $p$-value \\
\hline Age, $n(\%)$ & & & & & $.005^{*}$ \\
\hline [18-39] years & $162(42.0)$ & $69(42.6)$ & $39(24.1)$ & 54(33.3) & \\
\hline$[40-64]$ years & 198(51.3) & 120(60.6) & $27(13.6)$ & $51(25.8)$ & \\
\hline$>64$ years & $26(6.7)$ & $17(65.4)$ & $2(7.7)$ & $7(26.9)$ & \\
\hline Female gender, $\mathrm{n}(\%)$ & $266(67.3)$ & 139(52.3) & $44(16.5)$ & $83(31.2)$ & .191 \\
\hline $\mathrm{BMl}, \mathrm{km} / \mathrm{m}^{2}, \mathrm{n}(\%)$ & & & & & .304 \\
\hline Normal weight or underweight $(\mathrm{BMl}<25)$ & 99(45.8) & $60(60.6)$ & 15(15.2) & $24(24.2)$ & \\
\hline Overweight (BMI [25-30]) & 69(31.9) & $34(49.3)$ & $15(21.7)$ & 20(29.0) & \\
\hline Obesity $(\mathrm{BMI}>30)$ & $48(22.2)$ & $33(68.8)$ & $6(12.5)$ & $9(18.8)$ & \\
\hline Married, n(\%) & & & & & $.025^{*}$ \\
\hline No & $90(23.3)$ & $37(41.1)$ & $22(24.4)$ & $31(34.4)$ & \\
\hline Yes & 296(76.7) & 168(56.8) & $46(15.5)$ & $82(27.7)$ & \\
\hline Number of children, $\mathrm{n}(\%)$ & & & & & $.002^{*}$ \\
\hline$\leq 2$ children & 147(45.2) & $67(45.6)$ & $30(20.4)$ & $50(34.0)$ & \\
\hline$>2$ children & 178(54.8) & $116(65.2)$ & $25(14.0)$ & $37(20.8)$ & \\
\hline Place of residence, n(\%) & & & & & .544 \\
\hline Large town & $317(85.4)$ & 175(55.2) & $52(16.4)$ & $90(28.4)$ & \\
\hline Small town & $44(11.9)$ & $22(50.0)$ & $9(20.5)$ & 13(29.5) & \\
\hline Village & $10(2.7)$ & $3(30.0)$ & $3(20.0)$ & $4(40.0)$ & \\
\hline Educational level, n(\%) & & & & & .113 \\
\hline Secondary education or University & $94(30.3)$ & $42(44.7)$ & 18(19.1) & $34(36.2)$ & \\
\hline No scooling or primary school & 216(69.7) & 123(56.9) & $37(17.1)$ & $56(25.9)$ & \\
\hline Habitual activity, n(\%) & & & & & .712 \\
\hline Activelyemployed & $94(26.4)$ & $48(51.1)$ & 18(19.1) & 28(29.8) & \\
\hline Retired & $23(6.5)$ & $15(65.2)$ & $4(17.4)$ & $4(17.4)$ & \\
\hline Housework & $221(62.1)$ & $126(57.0)$ & $32(14.5)$ & $63(28.5)$ & \\
\hline Student & $18(5.1)$ & $8(44.4)$ & $4(22.2)$ & $6(33.3)$ & \\
\hline Social Health insurance, n(\%) & & & & & $.000^{*}$ \\
\hline No & 92(23.6) & 28(30.4) & $24(26.1)$ & $40(43.5)$ & \\
\hline Yes & 298(76.4) & $180(60.4)$ & $47(15.8)$ & $71(23.8)$ & \\
\hline
\end{tabular}

BMI Body Mass Index, $n$ number of cases, SD Standard Deviation, \% percentage Results are presented as mean \pm SD or $\mathrm{n}(\%)$ when appropriate *Significant, $P<0.05$ 
(45.8\%) and about 22.2\% were obese. Moreover, 69.7\% were illiterate or had primary school level and $30.3 \%$ had a secondary or higher educational level, and more significant part of the patient population were houseworker (62.1\%).

\section{Environmental and clinical factors}

The clinical and ecological factors that differed significantly with asthma control levels were: reasons of the current visit, smoking, concomitant diseases, comorbidities (rhinitis, conjunctivitis, GERD, and respiratory infections), number of crisis, and symptoms during 3 previous months (expectoration, wheezing, dyspnea) and allergy to animals (Table 2).

In fact, 48 (12.1\%) of patients had emergency visits because of an exacerbation of their asthma. The rate of distribution of aggravation through the groups of patients increased in a statistically significant way from 6 . $2 \%$ in controlled to $25 \%$ and $68.8 \%$ in partly and uncontrolled asthma respectively.

Around 259 (65.6\%) of patients had concomitant diseases, and its proportion differed significantly across the groups of patients with the higher value in controlled asthma group (46.7\%). As well, Rhinitis (59.7\%) and allergic conjunctivitis (44.6\%) were the most representative co-morbidities. The proportion of each co-morbiditie was statistically significantl for the groups of patients with the higher value in uncontrolled asthma group for GERD (47.4\%) and respiratory infections (52.3\%) and in controlled asthma group for rhinitis $(49.3 \%)$ and allergic conjunctivitis $(47.3 \%)$.

Indeed, $35 \%$ of patients would wake up during the night $(60.7 \%$ were uncontrolled and $39.3 \%$ partly controlled) and $29.4 \%$ had more than two crisis in a week with $86.1 \%$ in uncontrolled asthma. The proportion of expectoration, wheezing and dyspnea symptom during the 3 previous months, with the exception of noctucnal coughing, was higher and statistically significant in uncontrolled asthma. Farthermore, 19.8\% of patients suffered from an allergy to animals with lower values in the partly controlled asthma group (23.7\%).

Moreover, $83.4 \%$ of the patients in the study had never smoked, whereas $7.7 \%$ were ex-smokers. Also, only 35 of 392 patients were active smokers (represented by occasional smokers, and Light smoker) and most of them $(60 \%)$ with a controlled asthma.

As outlined in Table 2, the three groups of patients did differ concerning season of consultation, history of asthma, family history of asthma, passive smoking, nocturnal coughing and pulmonary function test. The mean duration of asthma was 18 years $( \pm 12.9)$ and $66 \%$ of patients were diagnosed more than 10 years ago. Furthermore, Pulmonary function tests were performed in only $11 \%$ of patients at the inclusion visit.
Interrogation alone is not enough to appreciate patient compliance, and we are deprived in this assessment unless using methods unbeknownst to the patient that ethics has forbidden. All patients received a therapeutic education. Poor adherence was reported in $8.3 \%$ of the included population. Failure to obey to the prescription dosage and treatment duration, especially in Ramadan, irregular consultations, unsuitable inhalation system, without neglecting the socioeconomic context namely the purchasing power; that does not often allows patients to acquire the treatment; adherence to medical coverage and the high burden of other concomitant chronic diseases were the leading causes.

\section{Factors associated with asthma control Univariate analysis}

Univariate ordinal logistic regression analysis using the asthma control as the dependent variable and all sociodemographic, environmental and clinical factors as independent variables are reported in Table 3.

Among the sociodemographic factors, the categories "being 40-64 years ols" (OR: 0.55; 95\% CI [0.37; 0.83]), "having more than two children" (OR: 0.47; 95\% CI [0.30; $0.71]$ ), "having none or primary educational level" (OR:0.61; 95\% CI [0.39; 0.97]) and "having a health insurance" (OR: 0.34; 95\% CI [0.22; 0.53]) have a significant negative association with the dependent category,in fact they are protective factors for "Uncontrolled asthma", in other words, these factors decrease the risk to have an "uncontrolled asthma" (OR $<1$ and $p$-value $<0.05)$. Also, being married (OR: $0.61 ; 95 \%$ CI $[0.36 ; 0.95])$ was associated with lower risk factors and better health status, even in the presence of many confounding effects. However, the remaining factors, sex, BMI, place of residence and occupation were not associated with asthma control in univariate analysis.

Among the environmental and clinical factors, having concomitant diseases (OR: 2.15 ; 95\% CI [1.43; 3.23]), having rhinitis (OR: 1.66; 95\% CI $[1.11 ; 2.5])$, having conjunctivitis (OR: $1.65 ; 95 \%$ CI $[1.11 ; 2.44]$ ), having gastroesopheal reflux (OR: 2.56 ; 95\% CI [1.37; 4.76]) and having respiratory infections (OR: $4.21 ; 95 \%$ CI $[2.50 ; 7.14]$ ) were found as a risk factors of asthma (OR $>1$ and $p$-value $<0.05)$. The protective factors for uncontrolled asthma was adherence to treatment (OR: $0.71 ; 95 \%$ CI $[0.24 ; 2.08])$. In contrast, the season for the consultation, the patient and family history of asthma, passive smoking and allergies to dust, mold, pollen or season variation were not associated with asthma control in univariate analysis.

\section{Multivariate analysis}

The final models were built using multivariable ordinal logistic regression with stepwise selection factors 
Table 2 Environmental and clinical characteristics of the study population according to levels of asthma control

\begin{tabular}{|c|c|c|c|c|c|}
\hline & $\begin{array}{l}\text { All } \\
n=396\end{array}$ & $\begin{array}{l}\text { Controlled } \\
n=211\end{array}$ & $\begin{array}{l}\text { Partly controlled } \\
n=72\end{array}$ & $\begin{array}{l}\text { Uncontrolled } \\
n=113\end{array}$ & $p$-value \\
\hline Season of consultation, n(\%) & & & & & .280 \\
\hline Summer & $69(17.5)$ & $44(63.8)$ & $10(14.5)$ & $15(21.7)$ & \\
\hline Automn & $129(32.7)$ & $62(48.1)$ & $26(20.2)$ & $41(31.8)$ & \\
\hline Winter & 155(39.3) & $82(52.9)$ & $25(16.1)$ & $48(31.0)$ & \\
\hline Spring & $41(10.4)$ & $21(51.2)$ & $11(26.8)$ & $9(22.0)$ & \\
\hline Reasons of the current visit, $\mathrm{n}(\%)$ & & & & & $.000^{*}$ \\
\hline A follow-up visit & $348(87.9)$ & 208(59.8) & $60(17.2)$ & $80(23.0)$ & \\
\hline Aggravation of asthma & $48(12.1)$ & $3(6.2)$ & $12(25.0)$ & $33(68.8)$ & \\
\hline History of asthma, mean $( \pm S D)$ & $11.4( \pm 9.7)$ & $12( \pm 9.9)$ & $10( \pm 9.5)$ & $11( \pm 9.5)$ & .331 \\
\hline Family history of asthma, n(\%) & & & & & .514 \\
\hline None & $226(58.2)$ & 115(50.9) & $42(18.6)$ & $69(30.5)$ & \\
\hline Yes (parents, grandparents, uncles and aunts) & 162(41.8) & $92(56.8)$ & $26(16.0)$ & $44(27.2)$ & \\
\hline Smoking habits, n(\%) & & & & & $.031 *$ \\
\hline Never smoker & $327(83.4)$ & 166(50.8) & $57(17.4)$ & 104(31.8) & \\
\hline Active smoker & $35(8.9)$ & $21(60.0)$ & $9(25.7)$ & $5(14.3)$ & \\
\hline Ex-smoker & $30(7.7)$ & $22(73.3)$ & $4(13.3)$ & $4(13.3)$ & \\
\hline Passive smoking, $\mathrm{n}(\%)$ & & & & & .881 \\
\hline No & 144(39.5) & $77(53.3)$ & $27(18.8)$ & $40(27.8)$ & \\
\hline Yes & $221(60.5)$ & $120(54.3)$ & $37(16.7)$ & $64(29.0)$ & \\
\hline Concomitant diseases, $\mathrm{n}(\%)$ & & & & & $.001^{*}$ \\
\hline No & 136(34.4) & $89(65.4)$ & $21(15.4)$ & 26(19.1) & \\
\hline Yes & 259(65.6) & $121(46.7)$ & $51(19.7)$ & 87(33.6) & \\
\hline \multicolumn{6}{|l|}{ Co-morbidities, n(\%) } \\
\hline Rhinitis & $221(59.7)$ & 109(49.3) & 44(19.9) & $68(30.8)$ & $.045^{*}$ \\
\hline Allergic conjunctivitis & $165(44.6)$ & $78(47.3)$ & $34(20.6)$ & $53(32.1)$ & $.039 *$ \\
\hline Gastroesophageal Reflux Disease & $38(9.6)$ & 12(31.6) & $8(21.1)$ & $18(47.4)$ & $.011^{*}$ \\
\hline Respiratory Infections & $65(16.5)$ & 13(20.0) & $18(27.7)$ & $34(52.3)$ & $.000^{*}$ \\
\hline Waking during the night, $\mathrm{n}(\%)$ & & & & & $.000^{*}$ \\
\hline No & $254(65.3)$ & 205(80.7) & 18(7.1) & $31(12.2)$ & \\
\hline Yes & 135(34.7) & $0(0.0)$ & 53(39.3) & $82(60.7)$ & \\
\hline Number of crisis, n(\%) & & & & & $.000 *$ \\
\hline$\leq 2 /$ week & 276(70.6) & 208(75.4) & $55(19.9)$ & $13(4.7)$ & \\
\hline$>2 /$ week & 115(29.4) & $0(0.0)$ & 16(13.9) & $99(86.1)$ & \\
\hline \multicolumn{6}{|l|}{ Symptoms during 3 previous months } \\
\hline Expectoration & $29(7.3)$ & $0(0.0)$ & $7(24.1)$ & $22(75.9)$ & $.000^{*}$ \\
\hline Wheezing & $92(72.4)$ & $0(0.0)$ & $36(39.1)$ & $56(60.9)$ & $.016^{*}$ \\
\hline Dyspnea & $109(27.5)$ & $0(0.0)$ & $38(34.9)$ & $71(65.1)$ & $.000 *$ \\
\hline Nocturnal coughing & $69(55.2)$ & $0(0.0)$ & $26(37.7)$ & $43(62.3)$ & .283 \\
\hline \multicolumn{6}{|l|}{ Allergy to, n(\%) } \\
\hline Dust & 295(76.8) & 153(51.9) & $56(19.0)$ & $86(29.2)$ & .199 \\
\hline Animals & 76(19.8) & $29(38.2)$ & 18(23.7) & $29(38.2)$ & $.008^{*}$ \\
\hline Mold & $233(60.7)$ & 123(52.8) & $41(17.6)$ & $69(29.6)$ & .767 \\
\hline
\end{tabular}


Table 2 Environmental and clinical characteristics of the study population according to levels of asthma control (Continued)

\begin{tabular}{|c|c|c|c|c|c|}
\hline & All & Controlled & Partly controlled & Uncontrolled & $p$-value \\
\hline & $n=396$ & $n=211$ & $n=72$ & $n=113$ & \\
\hline Pollen & 121(31.6) & $57(47.1)$ & 24(19.8) & $40(33.1)$ & .157 \\
\hline Smoke & $20(5.1)$ & $9(45.0)$ & $6(30.0)$ & $5(25.0)$ & .375 \\
\hline Medication & $40(10.1)$ & $25(62.5)$ & $3(7.5)$ & 12(30.0) & .168 \\
\hline Certain foods & $49(14.2)$ & 25(51.0) & $6(12.2)$ & 18(36.7) & .333 \\
\hline Season variation & $89(22.5)$ & $50(56.2)$ & $11(12.4)$ & 28(31.5) & .260 \\
\hline \multicolumn{6}{|l|}{ Other cause of crisis, n(\%) } \\
\hline Stressful event & $8(2.0)$ & $4(50.0)$ & $2(25.0)$ & $2(25.0)$ & .879 \\
\hline Emotion & $2(0.5)$ & $0(0.0)$ & $0(0.0)$ & $2(100.0)$ & .081 \\
\hline Effort & $16(4.1)$ & $6(37.5)$ & $3(18.8)$ & $7(43.8)$ & .348 \\
\hline Pulmonary function testing (FEV), n(\%) & & & & & .377 \\
\hline FEV $<80 \%$ & $29(64.4)$ & 16(55.2) & $7(24.1)$ & $6(20.7)$ & \\
\hline $\mathrm{FEV} \geq 80 \%$ & 16(35.6) & $6(37.5)$ & $7(43.8)$ & $3(18.8)$ & \\
\hline Adherence to treatment, $\mathrm{n}(\%)$ & & & & & .488 \\
\hline No & 12(3.0) & $6(50.0)$ & $1(8.3)$ & $5(41.7)$ & \\
\hline Yes & 384(97.0) & 205(53.4) & $71(18.5)$ & 108(28.1) & \\
\hline
\end{tabular}

FEV Forced Expiratory Volume in one second, $n$ number of cases, SD Standard Deviation;\%: percentage

Results are presented as mean \pm SD or $\mathrm{n}(\%)$ when appropriate

* Significant, $P<0.05$

method with asthma control as a dependent variable and as well as independent variables associated with asthma control in the univariate analysis. Table 4 represents the results of the multivariate analysis. Adjusted odds ratio and corresponding 95\% confidence intervals were calculated.

In this model, patients having respiratory infections (Adjusted-OR: 5.71; 95\% CI [2.39; 13.63]), having concomitant diseases (Adjusted-OR: 3.36; 95\% CI [0.99; 11.34]), allergic to animals (Adjusted-OR: 2.76, 95\% CI [1.36; 5.59], those adhered to treatment (Adjusted-OR: 0.07; 95\% CI [0.01; 0. 98]), having health insurance (Adjusted-OR: 0.41; 95\% CI $[0.18 ; 0.93]$ ) and having more than two children (AdjustedOR: 0.47 ; 95\% CI $[0.24 ; 0.93]$ ) remained significantly associated with ordered asthma control levels (all with $p$-value $<0.05)$.

However, no statistical association with asthma control was found regarding age, civil status, educational level, smoking, having rhinitis, GERD or conjunctivitis (all with $p$-value $>0.05)$.

\section{Discussion}

MOSAR study allows us to identify the asthmatic profile of the patients referred to the pneumology consultation of three hospitals in Rabat. Our study showed an asthmatic percentage among consultants for other reasons of $5.7 \%$ higher than the prevalence of asthma in Morocco (3.89\%) found by Benkheder et al. in the Maghreb study AIRMAG [19], which may be explained by the centralization of specialized consultation in the big cities,but resembling other countries with a permanent and continuous rise of this prevalence [20-22].

The study showed by Stempel et al. [23] which was focused on the fluctuation control of asthmatic patients over a three years period estimated that the majority of patients presented uncontroled signs during the duration of the disease. Cazzoletti et al. [24] reported in their European study on asthma control that the rate of uncontrolled patients ranged from 20\% (Iceland) to $67 \%$ (Italy).Almost two-third of asthmatic patients included in a study evaluating the degree of asthma control in Spain in 2006 were poorly controlled [25]. More recently, Vervloet et al. found a high rate of asthmatic patients with inadequate control of asthma in real life despite the fact that $95 \%$ of patients were treated with anti-asthmatics [26]. Our study revealsed that $29 \%$ of patients had uncontrolled asthma.

The female dominance observed in our sample of patients was also reported in the European cohort study ENFUMOSA [27] and by many authors in the Maghreb and elsewhere [3, 28-31].

Asthma affects all ages with varying prevalences from country to another. The average age of our patients was 42 years, with no significant difference between various control levels, was similar to the levels found in most studies [19, 30, 32]. In our sample of patients, the age group most affected was between 40 and 64 years (198patients (51.3\%)); in the French decennial survey, INSEE [28] it is rather beyond this age where there is a higher prevalence. 
Table 3 Factors in the univariate ordered logistic regression analysis for the respective asthma control categories

\begin{tabular}{|c|c|c|c|}
\hline & Unadjusted OR & $95 \% \mathrm{Cl}$ & $p$-value \\
\hline \multicolumn{4}{|l|}{ 1. Socio-demographic factors } \\
\hline Age (Referent ${ }^{\mathrm{a}}$ : [18-39]) & & & .008 \\
\hline [40-64] years & 0.55 & {$[0.37-0.83]$} & $.004^{*}$ \\
\hline$>64$ years & 0.48 & {$[0.20-1.11]$} & .085 \\
\hline Sex (Referent ${ }^{\mathrm{a}}$ : male) & 1.23 & {$[0.82-5.00]$} & .312 \\
\hline BMI (Referent ${ }^{\mathrm{a}}$ : normal weight or underweight) & & & .131 \\
\hline Overweight & 1.47 & {$[0.81-2.63]$} & .204 \\
\hline Obesity & 0.70 & {$[0.34-1.43]$} & .327 \\
\hline Married & 0.61 & {$[0.39-0.95]$} & $.029 *$ \\
\hline Number of children (Referent $t^{\mathrm{a}}: \leq 2$ ) & 0.47 & {$[0.30-0.71]$} & $.000^{*}$ \\
\hline Place of residence (Referent ${ }^{\mathrm{a}}$ : large town) & & & .384 \\
\hline Small town & 1.17 & {$[0.64-2.13]$} & .618 \\
\hline Village & 2.14 & {$[0.66-7.14]$} & .207 \\
\hline Educational level (Referent ${ }^{\mathrm{a}}$ :secondaryor university) & 0.61 & {$[0.39-0.97]$} & $.037^{*}$ \\
\hline Occupation (Referent ${ }^{\mathrm{a}}$ : actively employed) & & & .483 \\
\hline Retired & 0.55 & {$[0.22-1.39]$} & .209 \\
\hline Housework & 0.84 & {$[0.53-1.33]$} & .453 \\
\hline Student & 1.24 & {$[0.48-3.23]$} & .656 \\
\hline Health insurance & 0.34 & {$[0.22-0.53]$} & $.000^{*}$ \\
\hline \multicolumn{4}{|l|}{ 2. Environmental and clinical factors } \\
\hline Season of consultation(Referent ${ }^{\mathrm{a}}$ : summer) & & & .218 \\
\hline Automn & 1.83 & {$[1.03-3.23]$} & $.040^{*}$ \\
\hline Winter & 1.60 & {$[0.91-2,78]$} & .103 \\
\hline Spring & 1.44 & {$[0.67-3.03]$} & .349 \\
\hline History of asthma & 0.99 & {$[0.97-1.01]$} & .267 \\
\hline Family history of asthma & 0.81 & {$[0.55-1.19]$} & .283 \\
\hline Smoking habits(Referent ${ }^{\mathrm{a}}$ : never smoker) & & & $.015^{*}$ \\
\hline Active smoker & 0.59 & {$[0.29-1.19]$} & .140 \\
\hline Ex-smoker & 0.36 & {$[0.16-0.83]$} & $.017^{*}$ \\
\hline Passive smoking & 1.00 & {$[0.67-1.5]$} & .993 \\
\hline Concomitant diseases & 2.15 & {$[1.43-3.23]$} & $.000^{*}$ \\
\hline \multicolumn{4}{|l|}{ Co-morbidities } \\
\hline Rhinitis & 1.66 & {$[1.11-2.5]$} & $.014^{*}$ \\
\hline Allergic conjunctivitis & 1.65 & {$[1.11-2.44]$} & $.013^{*}$ \\
\hline Gastroesophageal reflux & 2.56 & {$[1.37-4.76]$} & $.003^{*}$ \\
\hline Respiratory Infections & 4.21 & {$[2.50-7.14]$} & $.000^{*}$ \\
\hline \multicolumn{4}{|l|}{ Allergy to: } \\
\hline Dust & 1.40 & {$[0.88-2.22]$} & .161 \\
\hline Animals & 2.01 & {$[1.25-3.23]$} & $.004^{*}$ \\
\hline Mold & 1.16 & {$[0.78-1.72]$} & .469 \\
\hline Pollen & 1.47 & {$[0.97-2.22]$} & .066 \\
\hline Season variation & 0.96 & {$[0.61-1.52]$} & .862 \\
\hline Adherence to treatment & 0.71 & {$[0.24-2.08]$} & $.042^{*}$ \\
\hline
\end{tabular}


Table 4 Factors in the multivariate ordered logistic regression analysis for the respective asthma control categories

\begin{tabular}{|c|c|c|c|}
\hline & Adjusted OR & $95 \% \mathrm{Cl}$ & $p$-value \\
\hline \multicolumn{4}{|l|}{ 1. Socio-demographic factors } \\
\hline \multicolumn{4}{|l|}{ Age (Referent ${ }^{a}$ : [18-39]) } \\
\hline$[40-64]$ years & 0.75 & {$[0.38-1.49]$} & .414 \\
\hline$>64$ years & 0.77 & {$[0.21-2.76]$} & .683 \\
\hline Married & 2.37 & {$[0.63-8.85]$} & .201 \\
\hline Number of children (Referent ${ }^{\mathrm{a}}$ : $\leq 2$ ) & 0.47 & {$[0.24-0.93]$} & $.030^{*}$ \\
\hline Educational level (Referent ${ }^{\mathrm{a}}$ : secondary or university) & 0.50 & {$[0.24-1.04]$} & .064 \\
\hline Health insurance & 0.41 & {$[0.18-0.93]$} & $.033^{*}$ \\
\hline \multicolumn{4}{|l|}{ 2. Environmental and clinical factors } \\
\hline \multicolumn{4}{|l|}{ Smoking (Referent ${ }^{\mathrm{a}}$ : never smoker) } \\
\hline Active smoker & 0.51 & [0.19-1.39] & .191 \\
\hline Ex smoker & 0.50 & {$[0.16-1.60]$} & .242 \\
\hline Concomitant diseases & 3.36 & {$[0.99-11.34]$} & $.050^{*}$ \\
\hline \multicolumn{4}{|l|}{ Co-morbidities } \\
\hline Rhinitis & 0.84 & {$[0.29-2.45]$} & .756 \\
\hline Allergic conjunctivitis & 1.00 & {$[0.49-2.03]$} & 1.00 \\
\hline Gastroesophageal Reflux Disease & 1.83 & {$[0.70-4.82]$} & .219 \\
\hline Respiratory Infections & 5.71 & {$[2.39-13.63]$} & $.000^{*}$ \\
\hline Allergy to animals & 2.76 & {$[1.36-5.59]$} & $.005^{*}$ \\
\hline Adherence to treatment & 0.07 & {$[0.01-0.98]$} & $.049 *$ \\
\hline
\end{tabular}

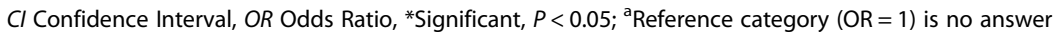

More than half of our patients were overweight or obese (54.1\%), but seems to note have influence on the asthma control level.The relationship between overweight and asthma was identified by analysis combining data from cohort studies; the risk of asthma was increased for men and for overweightwomen as well. Asthma risk is multiplied by 1.4 in overweight people without obesity and 1.9 in obese people [33].

Coogan et al. [22] found that a higher BMI is often associated with asthma and correlates with poor control, On the other hand, a cohort of 1265 patients in Sutherland et coll [34]. showed that obesity related to a more inadequate response to treatment than non-obese patients.

Nevertheless, there is still controversy to determine if asthma is secondary to obesity or if asthma and obesity are the result of conventional genetic factors, diet or physical inactivity [33, 34].

Loerbroks et al. [35] reported in a cohort of 5114 patients of 40 to 65 years old that asthma is associated with obesity and its prevalence is higher for obese women.

In our study, the prevalence of active smokers (8.9\%) was lower than that found in the literature where it ranges from 15 to $25 \%$ depending on the country [36, 37]. However, more than half of our patients undergoing passive smoking $(60.5 \%)$. This could be explained by two facts: first, the Moroccan socio-cultural context, where there is under-reporting of smoking for women and a relatively low prevalence (3.1\% versus $31.5 \%$ for men according to Nejarri et al.) [38]; second, that smokers who are prone to develop asthma either stop smoking because of respiratory symptoms before the diagnosis is made, or continue to smoke at a moderate rate because of their respiratory symptoms [39].

The active or passive smoking, was described as a risk factor for the onset of asthma and reduced control $[1,22,40-45]$. Moreover, it can alter the response to inhaled corticosteroids [46].

Three-quarters of our patients (72\%) had been consulted in autumn or winter; the high humidity could explain this in the city of Rabat. Similarly, according to a Belgian investigation [47], $5.1 \%$ of households in the Brussels region say they were embarrassed at home in the last 12 months of the study by a moisture problem.

This combination of moisture and the prevalence of asthma symptoms was explained. The proliferation of mites or molds is one of the possible explanations for this relationship [48].

While some countries such as France do not know any difference between the prevalence of asthma with the seasons [28]; there is a resurgence of crises during the pollen season for others $[28,49,50]$. 
According to Apter et al. [42] atopy is often related to asthma. This relationship is due to development of societies [51].

In our study the presence of at least one concomitant disease was found in more than half of patients (65.6\%). Allergic rhinitis was predominantly represented (59.7\%) and was three times higher than the French decenal investigation (21.6\%) [10].

In the ATHMOS study by Vervloet and al. [26] confirm that symptoms of rhinitis were associated with uncontrolled asthma that was previously shown by Barros et al [52] Additionally, the presence of rhinitis predicted the development of asthma [53]. In our study, rhinitis was associated with controlled asthma. However, patients with allergic rhinits in MOSAR study were treated according to ARIA guidelines, and untreated patients or non-compliance patients still risk factor for uncontrolled asthma. This was also described by Wallaert which reports that well treated rhinitis improves asthma control [54].

In more than half of our patients with at least one comorbidity, we found a good asthma control, while Apter and others reported the opposite in their articles [42, 55, 56].

The GERD was found in $9.6 \%$ of patients. Although it is usually considered as risk factor and poor asthma control [57], for Didier et al. [58], it is not justified to be present if there are no digestive symptoms.

Only the one-third of our patients reported nocturnal crisis, while the majority of patients had less than two attacks per week, this can be interpreted by the high number of patients having controlled asthma in our sample.

The measuring of the FEV (Forced Expiratory Volume in one second) was not possible in $89 \%$ of the patients, due to poor clinical conditions or difficulties to measure; 35.6\% have a normal FEV.

Asthma duration remains underestimated (recall bias), and it often represents a risk of error [30] relatively short for most of our patients (11.4 \pm 9.7 years) in comparison with the study of Allegra et al. [17] conducted in Italy in $2011(16.9 \pm 13.4)$ years.

Pulmonary radiography is requested in the initial exploration to define diagnosis, but it is not a usual followup examination for asthma patients. By against, spirometry, is an examination which occupies an essential place both in the diagnosis and in the monitoring asthma [16], and should regulary be performed or at the request to assess the impact of asthma on lung function.

None of our patients had done laboratory tests, such as the rate of eosinophils in the blood or sputum; these tests were not routine examinations [59].

Therefore, the diagnosis of asthma was based on the presence of clinical symptoms as given in the latest Global Initiative of Asthma guidelines (GINA guidelines)
[16]. Dyspnea, Nocturnal coughing and wheezing were the symptoms found in our patients, in accordance with the review of literature [28].

The goal of asthma management is to achieve and maintain its control; knowing that the control level is fluctuating [23], our study only reflects its trend during the 42 months of our research.

According to the World Health Organization [3], asthma is incurable. However, adequate support allows to curb the disorder and gives the asthmatic patient a better quality of life, a appropriate care, especially for the comorbidities, rhinitis, GERD and respiratory infections associated with asthma,improves control level.

Asthma management remains unsteadily at the national plan compared to other countries $[15,60]$. The reasons for the inadequate quality of treatment is due to the combination of two factors; firstly the socioeconomic environment very particular developing countries with its outcomes: low purchasing power, inadequate health insurance and on the other hand the difficulties inherent in asthma patients: influence beliefs, poor adherence ..., and other extenuating factors.

We note that some factors circumstances associated with the level of control have not been discussed or evaluated in this work during our investigation. Exploration by the flowmeter (rudimentary gesture amounting respiratory function), the psychological impact and the doctor-patient relationship, therapeutic patient education (which develop asthma as recurrent acute illness and not as a chronic disease [61], household income that may be the leading cause of non-adherence were not taken in consideration for the study.

Multivariate ordinal regression analysis identified several independent factors associated with asthma control as shown in Fig. 2. Having respiratory infections, having concomitant diseases and to be allergic to animals were found as risk factors for asthma.

Patients with respiratory infections had 5.7 times more risk of having worse asthma control (uncontrolled or partly controlled asthma), Those with concomitant diseases showed 3.4 times more risk and those allergic to animals had 2.8 times more.

In contrast, adhered to treatment, having health insurance and having more than two children were found as protective factors for uncontrolled asthma. Adherence to treatment significantly increased the odds of being in controlled asthma category by $7 \%$. Regarding health insurance, patients having health insurance showed a better control of asthma, their odds to have controlled asthma was $40 \%$ times higher than those without controlled asthma. Finally, patients having more than 2 children were 50\% more likely to have a controlled asthma compared with those having 2 or fewer children. 


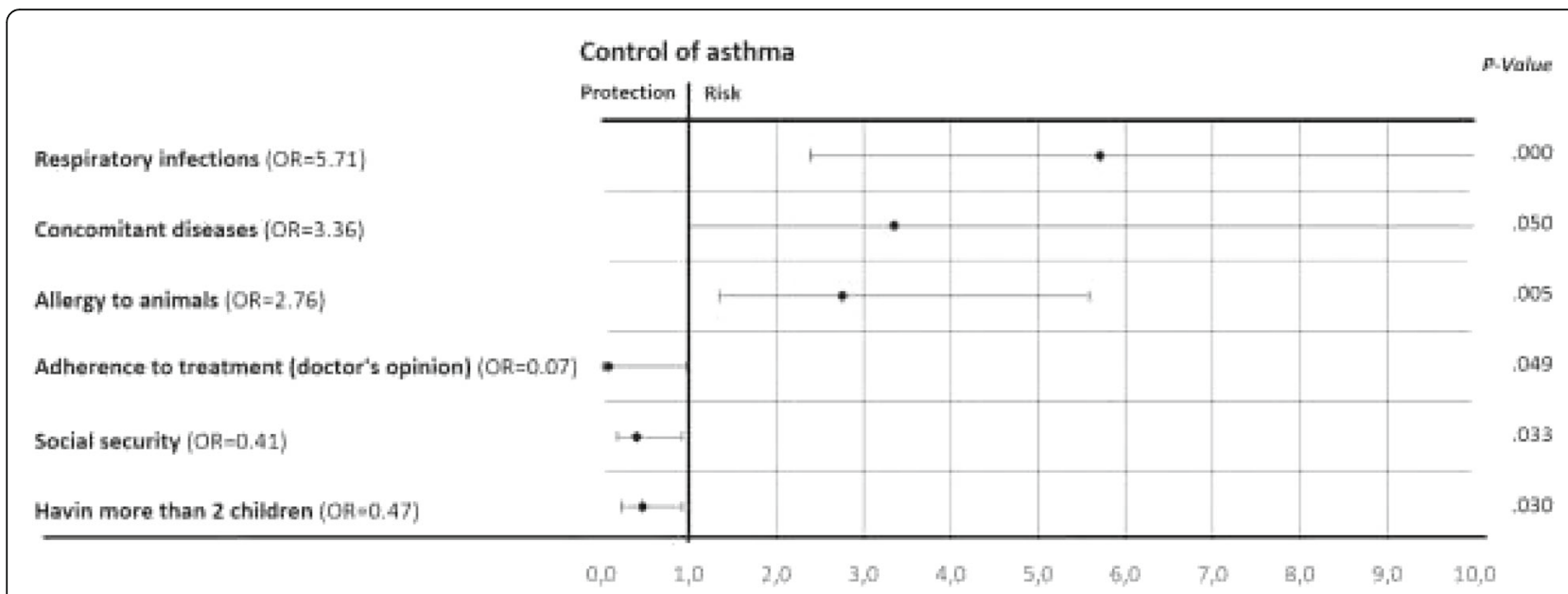

AOR: Adjasted Odds Ratio.

Fig. 2 Risk and protective factors for uncontrolled asthma

As limitation of the study, the absence of lung functions and chest RX could have impact on the trust of diagnosis. Radiography, it is not considered as essential test for asthma diagnosis according to GINA.

Also, FEV1 is not required for all patients but it alteration is considered for future risk. Howeve when we talk about control we mean clinical control.

\section{Conclusion}

The study has established a clinical-epidemiological profile of asthmatic patients in Rabat region-Morocco and examined the socio-demographic, environmental and clinical factors associated with asthma control in the region. Proportional odds model for ordinal logistic regression was used to identify possible contributory factors. The results of the study show that factors such as respiratory infections, concomitant diseases and animals allergy were perceived as risk factors for asthma. In contrast, adherence to treatment, health insurance and having more than two children was observed as protective factors for uncontrolled asthma.

This work constitutes a blank for the profiling and the asthma phenotype in Rabat region awaiting a generalization of the results by work nationally.

\section{Abbreviations}

AOR: Adjusted Odds Ratio; BMI: Body Mass Index; FEV: Forced Expiratory Volume in one second; GER: GastroEsopheal Reflux; GERD: Gastroesophageal Reflux Disease; GINA: Global INitiative of Asthma; OR: Odds Ratio: POM: Proportional Odds Model; SD: Standard Deviation

\section{Acknowledgements}

The authors would like to express their gratitude to Pr. Tawfik FASSI FIHRI for initiation of the study cohort and all the staff. The authors would also like to thank staff at Ibn Sina Hospital, Mohamed V Military Hospital and Moulay

Youssef Hospital for their contribution to the research and patient recruitment.
Availability of data and materials

The datasets generated and/or analysed during the current study available from the corresponding author on reasonable request.

\section{Ethics committee registration}

Ethics Committee for Biomedical Research (CERB) of the Faculty of Medicine and Pharmacy of Rabat: 42/12-01-2013.

\section{Authors' contributions}

IG, ACH, LH, SA and YC contributed to conception and design, clinical analysis and interpretation of data, and the writing of the manuscript. AC, KR and $A Z$ contributed mathematical analysis and interpretation of data, and the writing of the manuscript. SAE and ML contributed to patient recruitment. AMBR contributed by a language correction (as native speaker) and by a critical reading. All authors read and approved the final manuscript.

Ethics approval and consent to participate

The study was approved by Ethics Committee for Biomedical Research (CERB) of the Faculty of Medicine and Pharmacy of Rabat and an informed consent for participating in the study was also obtained from all patients.

\section{Competing interests}

The authors declare that they have no competing interests.

\section{Publisher's Note}

Springer Nature remains neutral with regard to jurisdictional claims in published maps and institutional affiliations.

\section{Author details}

${ }^{1}$ Research team of Pharmacoepidemiology \& Pharmacoeconomics, Laboratory of Pharmacology and Toxicology, Faculty of Medicine and Pharmacy, Mohammed V University, Rabat, Morocco. ${ }^{2}$ Faculty of Health Sciences, International University of Casablanca, Bouskoura, Morocco. ${ }^{3}$ Laboratory of Applied Mathematics, Faculty of Sciences, Mohammed V University, Rabat, Morocco. ${ }^{4}$ Unit of training and research in Nutrition and Food Sciences, Faculty of Medicine and Pharmacy, Mohammed V University, Rabat, Morocco. ${ }^{5}$ Department of Pneumology, Ibn Sina Hospital, Rabat, Morocco. ${ }^{6}$ Department of Pneumology, Mohamed V Military Hospital, Rabat, Morocco. ${ }^{7}$ Department of Pneumology, Moulay Youssef Hospital, Rabat, Morocco. ${ }^{8}$ Department of Languages, International University of Casablanca, Bouskoura, Morocco. ${ }^{9}$ Doctoral Student in Psychology, Walden University, Minneapolis, USA. 


\section{Received: 26 October 2017 Accepted: 11 April 2018 Published online: 24 April 2018}

\section{References}

1. Thèmes de santé : Asthme. 24-10-2012]; Available from: http://www.who.int/ topics/asthma/fr/.

2. Kovar l, et al. Perinatal lead and cadmium burden in a British urban population. Arch Dis Child. 1984;59(1):36-9.

3. Nafti $\mathrm{S}$, et al. Prevalence of asthma in North Africa: the asthma insights and reality in the Maghreb (AIRMAG) study. Respir Med. 2009;103(Suppl 2):S2-11.

4. Masoli $\mathrm{M}$, et al. The global burden of asthma: executive summary of the GINA dissemination committee report. Allergy. 2004;59(5):469-78.

5. Urrutia I, et al. Changes in the prevalence of asthma in the Spanish cohort of the European Community Respiratory Health Survey (ECRHS-II). Arch Bronconeumol. 2007:43(8):425-30.

6. von Mutius E. Of attraction and rejection-asthma and the microbial world. N Engl J Med. 2007;357(15):1545-7.

7. Yan DC, et al. Prevalence and severity of symptoms of asthma, rhinitis, and eczema in 13- to 14-year-old children in Taipei, Taiwan. Ann Allergy Asthma Immunol. 2005;95(6):579-85.

8. Asher $\mathrm{Ml}$, et al. Worldwide time trends in the prevalence of symptoms of asthma, allergic rhinoconjunctivitis, and eczema in childhood: ISAAC phases one and three repeat multicountry cross-sectional surveys. Lancet. 2006; 368(9537):733-43.

9. Carvajal-Uruena I, et al. Geographic variation in the prevalence of asthma symptoms in Spanish children and adolescents. International Study of Asthma and Allergies in Childhood (ISAAC) Phase 3, Spain. Arch Bronconeumol. 2005;41(12):659-66.

10. Delmas, M.C., C. Fuhrman, and S. pour le groupe epidemiologie et recherche clinique de la, [Asthma in France: a review of descriptive epidemiological data]. Rev Mal Respir, 2010. 27(2): p. 151-159.

11. Dujardin G, B.A., Prise en charge: Présentation du réseau asthme et Allergies de Roubaix. Air Pur, 2007. №71(Premier semestre): p. 41-46.

12. Combescure $C$, et al. Assessment of variations in control of asthma over time. Eur Respir J. 2003;22(2):298-304

13. Charriot J, et al. Thérapies ciblées dans l'asthme sévère: À la découverte de nouvelles molécules. Rev Mal Respir. 2013:30(8):613-26.

14. Vervloet, D. and A. Magnan, Traité d'allergologie. 2003: Flammarion médecine-sciences.

15. Ghanname I, et al. Trends in the use of antiasthmatic medications in Morocco (1999-2010). Spring. 2013;2(1):82.

16. (GINA), G.i.f.a., Global Strategy for Asthma Management and Prevention 2016 update.

17. Allegra $L$, et al. Real-life prospective study on asthma control in Italy: crosssectional phase results. Respir Med. 2012;106(2):205-14.

18. Prévot $L$, et al. Prise en charge médicale des patients asthmatiques. Enquête de pratique auprès d'assurés sociaux et de médecins de la Réunion. Revue Médicale de l'Assurance Maladie. 2003;34(1):3-13.

19. Benkheder A, et al. Control of asthma in the Maghreb: results of the AIRMAG study. Respir Med. 2009;103:S12-20.

20. Bukstein D, et al. Asthma end points and outcomes: what have we learned? J Allergy Clin Immunol. 2006;118(4):S1-S15.

21. Peters SP, et al. Real-world evaluation of asthma control and treatment (REACT): findings from a national web-based survey. J Allergy Clin Immunol. 2007:119(6):1454-61.

22. Coogan PF, et al. Body mass index and asthma incidence in the black Women's health study. J Allergy Clin Immunol. 2009;123(1):89-95.

23. Stempel DA, et al. Patterns of asthma control: a 3-year analysis of patient claims. J Allergy Clin Immunol. 2005;115(5):935-9.

24. Cazzoletti $L$, et al. Asthma control in Europe: a real-world evaluation based on an international population-based study. J Allergy Clin Immunol. 2007; 120(6):1360-7.

25. Diez JdM, et al. Control of persistent asthma in Spain: associated factors. J Asthma. 2008;45(9):740-6.

26. Vervloet $\mathrm{D}$, et al. Factors associated with poorly controlled asthma among adults in France. Revue Française d'Allergologie. 2014;54(6):428-37.

27. Group, E.S., The ENFUMOSA cross-sectional European multicentre study of the clinical phenotype of chronic severe asthma. Eur Respir J, 2003. 22(3): p. 470-477.

28. Delmas, M.-C., et al., Asthme: prévalence et impact sur la vie quotidienne. Analyse des données de l'enquête décennale santé, 2003.
29. Alaoui-Yazidi A, et al. Profil des allergies respiratoires et dermatologiques chez le personnel de santé au Maroc. Revue française d'allergologie et d'immunologie clinique. 2003;43(6):377-84.

30. Torén $\mathrm{K}$, et al. Adult-onset asthma in West Sweden-incidence, sex differences and impact of occupational exposures. Respir Med. 2011;105(11): 1622-8.

31. Subbarao P, Mandhane P, Sears MR. Asthma: epidemiology, etiology and risk factors. Can Med Assoc J. 2009;181(9):E181-90.

32. de Carvalho-Pinto RM, et al. Clinical characteristics and possible phenotypes of an adult severe asthma population. Respir Med. 2012;106(1):47-56.

33. Beuther DA, Sutherland ER. Overweight, obesity, and incident asthma: a meta-analysis of prospective epidemiologic studies. Am J Respir Crit Care Med. 2007:175(7):661-6.

34. Sutherland, E., et al. Comparative effect of body mass index on response to asthma controller therapy. in Allergy and Asthma Proceedings. 2010. OceanSide Publications, Inc.

35. Loerbroks A, et al. Obesity and adult asthma: potential effect modification by gender, but not by hay fever. Ann Epidemiol. 2008;18(4):283-9.

36. Annesi-Maesano I, et al. Increased prevalence of asthma and allied diseases among active adolescent tobacco smokers after controlling for passive smoking exposure. A cause for concern? Clin Exp Allergy. 2004; 34(7):1017-23.

37. Hylkema M, et al. Tobacco use in relation to COPD and asthma. Eur Respir J. 2007;29(3):438-45

38. Nejjari $C$, et al. Prevalence and demographic factors of smoking in Morocco. International journal of public health. 2009;54(6):447-51.

39. Piipari R, et al. Smoking and asthma in adults. Eur Respir J. 2004;24(5):734-9.

40. Busse WW, Rosenwasser $\amalg$. Mechanisms of asthma. J Allergy Clin Immunol. 2003;111(3):S799-804.

41. Haughney J, et al. Achieving asthma control in practice: understanding the reasons for poor control. Respir Med. 2008;102(12):1681-93.

42. Apter AJ. Advances in the care of adults with asthma and allergy in 2007. J Allergy Clin Immunol. 2008;121(4):839-44.

43. McLeish AC, Zvolensky MJ. Asthma and cigarette smoking: a review of the empirical literature. J Asthma. 2010;47(4):345-61.

44. Mohammad $Y$, et al. Impact of active and passive smoking as risk factors for asthma and COPD in women presenting to primary care in Syria: first report by the WHO-GARD survey group. International journal of chronic obstructive pulmonary disease. 2013;8:473.

45. Mohammad Y. Passive smoking interference with wheezing and asthma: short review of current knowledge. Pulmonology and Respiratory Research. 2015;3(1):2.

46. Thomson NC, Chaudhuri R. Asthma in smokers: challenges and opportunities. Curr Opin Pulm Med. 2009;15(1):39-45.

47. Bayingana K, et al. Enquête de Santé par interview. In: Belgique, vol. 2004 Bruxelles: Institut Scientifique de Santé Publique; 2006.

48. Weiland $\mathrm{S}$, et al. Climate and the prevalence of symptoms of asthma, allergic rhinitis, and atopic eczema in children. Occup Environ Med. 2004; 61(7):609-15.

49. Tobias A, et al. Short term effects of airborne pollen concentrations on asthma epidemic. Thorax. 2003:58(8):708-10.

50. D'Amato G. Effects of climatic changes and urban air pollution on the rising trends of respiratory allergy and asthma. Multidisciplinary respiratory medicine. 2011;6(1):28

51. Corrigan C. Mechanisms of intrinsic asthma. Curr Opin Allergy Clin Immunol. 2004;4(1):53-6.

52. Barros $\mathrm{LL}$, et al. Obesity and poor asthma control in patients with severe asthma. J Asthma. 2011:48(2):171-6.

53. Leynaert $B$, et al. Perennial rhinitis: an independent risk factor for asthma in nonatopic subjects: results from the European Community respiratory health survey. J Allergy Clin Immunol. 1999;104(2):301-4.

54. Wallaert B. Le rôle de la rhinite dans les exacerbations de l'asthme. Revue Francaise d'Allergologie. 2009;49:S53-6.

55. Apter AJ. Advances in adult asthma diagnosis and treatment and HEDQ in 2010. J Allergy Clin Immunol. 2011;127(1):116-22.

56. Chanez $\mathrm{P}$, et al. Severe asthma in adults: what are the important questions? J Allergy Clin Immunol. 2007;119(6):1337-48.

57. Scheinmann P. Asthme et reflux gastro-œsophagien. Revue française d'allergologie et d'immunologie clinique. 1984;24(4):211-4.

58. Didier $A$, Têtu L, Miguérès $M$. Asthme et reflux gastro-œsophagien. Revue française d'allergologie et d'immunologie clinique. 2004;44(1):79-82. 
59. Roche N, et al. Clinical practice guidelines: medical follow-up of patients with asthma_adults and adolescents. Respir Med. 2005;99(7):793-815.

60. Ghanname I, et al. Factors influencing anti-asthmatic generic drug consumption in Morocco: 1999-2010. Spring. 2014;3:192.

61. PISON C, DEVOUASSOUX G, PIN I. L'asthme suivi en consultation: Prise en charge de l'asthme chez l'adulte. La Revue du praticien. 2001;51(5):493-501.

Ready to submit your research? Choose BMC and benefit from:

- fast, convenient online submission

- thorough peer review by experienced researchers in your field

- rapid publication on acceptance

- support for research data, including large and complex data types

- gold Open Access which fosters wider collaboration and increased citations

- maximum visibility for your research: over $100 \mathrm{M}$ website views per year 